\title{
Considerações sobre os desafios da escola básica atual: reflexões para uma sociedade mais plural
}

\author{
Considerations about the challenges of the current basic school: Reflections for a more plural \\ society
}

Consideraciones sobre los desafíos de la escuela básica actual: Reflexiones para una sociedad más plural

Recebido: 18/03/2021 | Revisado: 24/03/2021 | Aceito: 01/04/2021 | Publicado: 11/04/2021

Tássia Fernandes Ferreira

ORCID: https://orcid.org/0000-0002-2750-8897 Universidade Estadual do Ceará, Brasil E-mail: tassiaffer@gmail.com

Kátia Maria de Moura Evêncio

ORCID: https://orcid.org/0000-0003-3070-0086 Universidade Estadual do Piauí, Brasil

E-mail: professorakatiamoura@gmail.com

Alba Patrícia Passos de Sousa

ORCID: https://orcid.org/0000-0002-0453-5550 Universidade Federal do Piauí, Brasil E-mail: alba2sousa@ufpi.edu.br

Lana Priscila Souza

ORCID: https://orcid.org/0000-0003-1921-1396

Secretaria de Educação do Estado do Ceará, Brasil E-mail: lanapriscilasouza@yahoo.com.br

\begin{abstract}
Resumo
O trabalho aqui apresentado tem gênese em estudos desenvolvidos para uma pesquisa de dissertação, no âmbito do curso de mestrado em Educação Brasileira da Universidade Federal do Ceará (UFC), realizado no período de 2015 a 2017, pela autora principal. Posto isto, o presente artigo foi construído a partir do resgate da referida temática, e configura-se como uma pesquisa exploratória, com abordagem qualitativa, cujo embasamento teórico se deu com foco, principalmente, nos escritos de Bernard Charlot e nos marcos legais educacionais. Tivemos como objetivos centrais apresentar e discutir mudanças sofridas pela escola básica pública ao longo dos anos, a nível de Brasil, e seus impactos na educação; bem como refletir acerca dos desafios enfrentados pela escola, considerando seus contextos e sujeitos, em especial, os professores, na busca por uma sociedade mais plural, a partir de uma formação cidadã. Concluímos que, dentro da dinâmica social constantemente transformada - na qual se encontra a escola a qual nos referimos, com suas novas exigências, seu novo tipo de aluno e suas novas atribuições docentes - apesar do que estabelecem os documentos legais, acerca de uma formação cidadã, muitos são os caminhos e as contradições em busca de uma educação que possibilite a promoção de uma sociedade mais plural.
\end{abstract}

Palavras-chave: Escola básica atual; Desafios; Escola pública; Sociedade; Professores.

\begin{abstract}
The work presented here has its genesis in studies developed for a dissertation research, within the scope of the master's course in Brazilian Education at the Federal University of Ceara (UFC), carried out from 2015 to 2017, by the main author. That said, this article was built from the rescue of the aforementioned theme, and is configured as an exploratory research, with a qualitative approach, whose theoretical basis was focused, mainly, on the writings of Bernard Charlot and on the educational legal frameworks. We had as central objectives to present and discuss changes suffered by the public basic school over the years, at the level of Brazil, and its impacts on education; as well as reflecting on the challenges faced by the school, considering their contexts and subjects, especially teachers, in the search for a more plural society, based on a citizen formation. We conclude that, within the constantly transformed social dynamics - in which the school we are referring to is found, with its new requirements, its new type of student and its new teaching assignments - despite what the legal documents establish, about a citizen formation, there are many paths and contradictions in search of an education that enables the promotion of a more plural society.
\end{abstract}

Keywords: Current basic school; Challenges; Public school; Society; Teachers. 


\begin{abstract}
Resumen
El trabajo aquí presentado tiene su génesis en estudios desarrollados para una investigación de tesis, en el ámbito de la maestría en Educación Brasileña de la Universidad Federal de Ceará (UFC), realizada de 2015 a 2017, por el autor principal. Dicho esto, este artículo se construyó a partir del rescate de la temática antes mencionada, y se configura como una investigación exploratoria, con enfoque cualitativo, cuya base teórica se centró, principalmente, en los escritos de Bernard Charlot y en los marcos legales educativos. Teníamos como objetivos centrales presentar y discutir los cambios sufridos por la escuela básica pública a lo largo de los años, a nivel de Brasil, y sus impactos en la educación; así como reflexionar sobre los desafíos que enfrenta la escuela, considerando sus contextos y materias, especialmente los docentes, en la búsqueda de una sociedad más plural, basada en una formación ciudadana. Concluimos que, dentro de la dinámica social en constante transformación -en la que se encuentra la escuela a la que nos referimos, con sus nuevos requerimientos, su nuevo tipo de alumno y sus nuevas tareas docentes- a pesar de lo que establecen los documentos legales, sobre una formación ciudadana, hay muchos caminos y contradicciones en la búsqueda de una educación que posibilite la promoción de una sociedad más plural.
\end{abstract}

Palabras clave: Escuela básica actual; Desafíos; Escuela pública; Sociedad; Profesores.

\title{
1. Introdução
}

As discussões acerca das questões que englobam a escola básica atual fazem-se oportunas no contexto acadêmicosocial de toda e qualquer nação, na medida em que, enquanto instituição social, a escola não se desvincula do contexto ao qual está inserida. Em vista disso, acaba por ter a incumbência de responder as demandas que lhe chegam, decorrentes das transformações nas esferas política, econômica, cultural, social que insidem sobre si.

Nessa direção, os objetivos centrais do presente artigo consistem em apresentar e discutir mudanças sofridas pela escola básica pública ao longo dos anos, a nível de Brasil, e seus impactos na educação; bem como refletir acerca dos desafios enfrentados pela escola, considerando seus contextos e sujeitos, em especial, os professores, na busca por uma sociedade mais plural, a partir de uma formação cidadã.

O presente artigo foi desenvolvido a partir de um estudo mais amplo, realizado no âmbito de uma pesquisa de mestrado em Educação Brasileira, da Universidade Federal do Ceará (UFC), cursado por uma das autoras deste trabalho. A justificativa para o resgate e a atualização dessa temática dá-se pela importância de atentar para as diversas questões que permeiam as discussões acerca da escola, dos sujeitos e dos contextos que a compõem, uma vez que tais questões impactam direta ou indiretamente na constituição da sociedade.

\section{Metodologia}

Do ponto de vista metodológico, a pesquisa é do tipo exploratória, "na qual o investigador vai propondo um novo discurso interpretativo para o fenômeno que descreve" (Minayo, 2016, p.17). A abordagem caracteriza-se como qualitativa, uma vez que esta "responde a questões particulares", além de abranger diversos significados e "um nível de realidade que não pode ser quantificado" explana Minayo (2016, p.20).

González (2020, p.2) explica que “a expressão Pesquisa Qualitativa quando usada de forma geral, não faz referência a uma entidade unitária; pelo contrário, nesse caso tem um caráter polissêmico porque refere práticas várias de indagação do social. Portanto, o escopo da pesquisa qualitativa é amplo e variado". O autor esclarece ainda que pesquisas dessa natureza têm, entre algumas de suas características, o fato de que:

(a) estão interessadas na essência dos processos sociais; (b) concebem as situações sociais como um sistema com alto nível de complexidade; (c) os pesquisadores adotam uma visão sistêmica da realidade; (d) não estabelecem um modelo rígido, nem prescrevem um esquema estruturado tipo receita de cozinha, mas o processo de pesquisa é desenvolvido com grande flexibilidade [...] (González, 2020, p.5). 
No que tange ao seu desenvolvimento, como acima mencionado, as leituras tiveram início durante a escrita de uma dissertação de mestrado, defendida em 2017. A partir de uma retomada dos estudos realizados à época, atualizamos as leituras, reorganizando os objetivos e focando o olhar sobre pontos que os contemplassem, de maneira mais direta, como requerem a escrita e a estrutura de artigos científicos. Estes, segundo Pereira, Shitsuka, Parreira e Shitsuka (2018, p.36) "são documentos científicos que apresentam textos atuais sobre experiências realizadas, relatos de casos, revisões de literatura etc.”. Assim como pesquisas mais amplas, "são também sucessões de argumentos, mas de modo mais simplificado e contendo somente as informações necessárias ao bom entendimento, mas de modo menos volumoso [...]” (p.36).

Como poderá ser observado, dedicamos atenção especial à esfera pública e enfocamos as décadas de 50 a 80, isto pela evidente agregação entre os contextos político e educacional, bem como as mudanças significativas que decorreram a partir de tais décadas.

Como referencial teórico, recorremos aos estudos de Bernard Charlot (2013a; 2013b), dialogando também com as contribuições de Libâneo (1998), Nóvoa (2007), além de marcos legais da educação brasileira, a saber: Leis de Diretrizes e Bases da Educação Nacional (Lei n. 5.692, 1971 \& Lei n. 9.394ㄹ, 1996a; 1996b), Diretrizes Curriculares Nacionais da Educação Básica (2013), Base Nacional Comum Curricular (instituída pela Resolução CNE/CP n. 2/2017), Constituição Federal (1988), entre outras legislações e também autores que discorrem sobre a temática aqui proposta.

\section{Breve Retomada do Contexto Político Educacional das Décadas de 50 a 80 e a Nova Escola}

\section{Básica}

Em linhas gerais, com as mudanças ocorridas no Estado brasileiro no cenário político das décadas de 50 e 60 , a escola, no que tange ao tipo de educação que se propunha a ofertar, também mudou. Antes desse período, e também antes da segunda grande Guerra Mundial (1939-1945), percebia-se o Estado como um Estado educador, ao passo que pensava a educação "em termos de construção da nação, paz social, inculcação de valores" (Charlot, 2013b, p.39). Após esse período, o Estado passou a ser desenvolvimentista, também colocando a educação a favor de seus interesses, mas agora numa lógica econômica de desenvolvimento.

Nessa perspectiva, e sem a lógica da globalização (que só viria a se concretizar posteriormente) ocorreu um processo que ficou conhecido como "massificação do ensino", que corresponde à grande expansão do acesso público à escola. A ideia era que, cada vez mais, um número maior de pessoas fosse escolarizado, a fim de atender à demanda da lógica econômica e social do desenvolvimento do país, o que gerou agrado às classes mais abastadas e possibilidades às menos favorecidas, como afirma Charlot (2013b) ao explanar a trajetória da mudança pela qual a educação brasileira passou, de acordo com o tratamento que o governo lhe dera.

Segundo o autor, no final da década de 70 e, de forma mais específica, na década de 80, o Estado desenvolvimentista deu lugar a um Estado regulador, passando a ter um outro trato com a educação. Dessa maneira, a educação agora seguia a lógica da qualidade e da globalização, o que se configura como uma lógica ainda socioeconômica, muito embora não tanto quanto a anterior. De toda forma, ainda assim, essa lógica requeria sujeitos aptos a desenvolver papéis exigidos pelas mudanças que ocorriam, o que implicava na formação de alunos que atendessem às demandas da realidade do país e, num contexto mais amplo, do mundo, naquele momento econômico e social. No geral, isso significava uma formação escolar pautada na qualificação, a fim de que os alunos (que são, antes de tudo, sujeitos sociais e, portanto, possíveis trabalhadores e consumidores) fossem capazes tanto de atender às exigências de produção, como de utilizar os produtos nela desenvolvidos.

\footnotetext{
${ }^{1}$ A referida lei data do ano de 1996, todavia, por nos referirmos tanto à sua versão original, quanto à sua versão modificada (mais atual), utilizamos a diferenciação 1996a e 1996b, respectivamente.
} 
No que tange ao termo "escola básica atual", ressaltamos que nos referimos a essa escola que decorre da gama de mudanças pelas quais o país passou, ao longo dos anos, em especial, com o processo de democratização do ensino, com maior demarcação a partir da Lei de Diretrizes e Bases da Educação Nacional de 1971 (LDBEN) (Lei n. 5.692, 1971). Na referida lei, o governo sancionou a obrigatoriedade da educação escolar pública dos sete aos 14 anos (1971), antigo primeiro grau, muito embora não houvesse ainda uma política efetiva de responsabilização às autoridades e familiares/responsáveis competentes para o caso do não cumprimento dessa determinação.

Posteriormente, a expansão do acesso ao ensino médio é determinada pela nova LDBEN, no ano de 1996 (Lei n. 9.394, 1996) que, depois de anos de discussões, sendo sete de tramitação no Congresso, determinava em seu artigo $4^{\circ}$ a "progressiva extensão da obrigatoriedade e gratuidade ao ensino médio" (1996a). Ao longo de 25 anos da referida lei, muitas foram as alterações e revogações no que tange, entre outros pontos, ao ensino médio público. Vejamos, abaixo, o artigo $4^{\circ}$ atualizado, contendo as legislações correspondentes:

Art. $4^{\circ} \mathrm{O}$ dever do Estado com educação escolar pública será efetivado mediante a garantia de:

I - educação básica obrigatória e gratuita dos 4 (quatro) aos 17 (dezessete) anos de idade, organizada da seguinte forma: (Redação dada pela Lei $n^{\circ} 12.796$, de 2013)

a) pré-escola; (Incluído pela Lei $n^{\circ} 12.796$, de 2013)

b) ensino fundamental; (Incluído pela Lei $n^{\circ} 12.796$, de 2013)

c) ensino médio; (Incluído pela Lei n ${ }^{\circ} 12.796$, de 2013)

II - educação infantil gratuita às crianças de até 5 (cinco) anos de idade; (Redação dada pela Lei no 12.796, de 2013)

III - atendimento educacional especializado gratuito aos educandos com deficiência, transtornos globais do desenvolvimento e altas habilidades ou superdotação, transversal a todos os níveis, etapas e modalidades, preferencialmente na rede regular de ensino; (Redação dada pela Lei no 12.796, de 2013)

IV - acesso público e gratuito aos ensinos fundamental e médio para todos os que não os concluíram na idade própria; (Redação dada pela Lei no 12.796, de 2013) [...] (1996b).

Charlot (2013b) comunica que, entre os grandes desafios a serem enfrentados pela escola atual, decorrentes das modificações sociais contemporâneas e da consequente expansão do ensino, está o fato de ter surgido uma nova relação com o saber, resultante das mudanças provocadas pela democratização escolar. Nessa nova relação, e sob a lógica socioeconômica, é cada vez maior o número de alunos que frequentam a escola por mera necessidade de obter um diploma para, a partir dessa conquista, poder ingressar no mercado de trabalho. Tais alunos não encontram, na concepção do autor, sentido nem prazer na escola que têm "buscado". Nessa perspectiva, o autor faz duras críticas ao neoliberalismo e aos consequentes efeitos dessa política na educação, afirmando que:

Por ser a sociedade contemporânea envolvida em um processo de globalização neoliberal, a educação tende a ser considerada como uma mercadoria entre outras, em um mercado 'livre' no qual prevalece a lei da oferta, da demanda da concorrência. Em tal situação a escola pública sofre numerosos ataques [...] A lógica neoliberal da concorrência tende a reduzir a educação a uma mercadoria escolar a ser rentabilizada no mercado dos empregos e das posições sociais e isso faz com que formas de aprendizagem mecânicas e superficiais, desconectadas do sentido do saber e de uma verdadeira atividade intelectual, tendam a predominar (Charlot, 2013b, p. 59-60).

A lógica neoliberal, ao adentrar nos ditames da educação, traz consigo a enxurrada de mudanças focadas no desenvolvimento da economia, mas que nem sempre estão de acordo com o desenvolvimento do aluno enquanto sujeito, na perspectiva requerida pelos próprios documentos norteadores da educação, como as Diretrizes Curriculares Nacionais da Educação Básica (DCNEBs, 2013) - oriundas da já mencionada LDBEN de 1996 - e cujas que se referem ao ensino médio foram atualizadas em 2018, pela Resolução CNE/CEB n. 3/2018, tendo em vista as mudanças estruturais decorrentes da Lei do novo ensino médio (Lei n. 13.415, 2017), uma das leis que alteraram a referida LDBEN. 
Como destaque dos documentos aos quais nos referimos está também, junto às DCNEBs, a Base Nacional Comum Curricular (BNCC), instituída pela Resolução CNE/CP n. 2/2017 que, conforme detalhado no site do Ministério da Educação (MEC), norteia a (re)elaboração curricular, orientando sobre os conhecimentos essenciais, bem como competências, habilidades e aprendizagens visadas aos alunos da educação básica, em todas as suas etapas.

Nos atuais documentos legais educacionais, o norte é para a promoção de uma formação dos sujeitos no sentido de desenvolvimento global, com vistas à preparação não só para o trabalho, mas para o exercício cidadão e, com isso, a construção de uma sociedade mais plural, sustentável, democrática, ética, como depreende-se da BNCC (CNE/CP n. 2/2017). Vale lembrar que este documento tem base nos marcos legais como as já citadas LDBEN (Lei n. 9.394, 1996b) e DCNEBs (2013) e obviamente, a soberana Constituição Federal de 1988 (ou Constituição Cidadã, como ficou conhecida) que, em seu artigo 205, aponta que a educação visa, tanto a qualificação para o trabalho, como o desenvolvimento pleno da pessoa e seu preparo para exercer a cidadania (1988). A atual LDBEN, entre os diversos pontos que tocam a questão da formação do sujeito num caráter integral, traz em seu artigo 32, nos incisos indicados, que a formação cidadã no ensino fundamental ocorrerá mediante: “[...] III) o desenvolvimento da capacidade de aprendizagem, tendo em vista a aquisição de conhecimento e habilidades e a formação de atitudes e valores; IV) o fortalecimento dos vínculos de família, dos laços de solidariedade humana e de tolerância recíproca em que se assenta a vida social. [...]" (Lei n. 9.394, 1996b). Quanto às DCNEBs, optamos por reproduzir na íntegra um parágrafo que consideramos de grande importância para ilustrar o lugar da temática da formação, na perspectiva da cidadania, no documento:

Em um contexto marcado pelo desenvolvimento de formas de exclusão cada vez mais sutis e humilhantes, a cidadania aparece hoje como uma promessa de sociabilidade, em que a escola precisa ampliar parte de suas funções, solicitando de seus agentes a função de mantenedores da paz nas relações sociais, diante das formas cada vez mais amplas e destrutivas de violência. Nessa perspectiva e no cenário em que a escola de Educação Básica se insere e em que o professor e o estudante atuam, há que se perguntar: de que tipo de educação os homens e as mulheres dos próximos 20 anos necessitam, para participarem da construção desse mundo tão diverso? A que trabalho e a que cidadania se refere? Em outras palavras, que sociedade florescerá? Por isso mesmo, a educação brasileira deve assumir o desafio de propor uma escola emancipadora e libertadora (2013, p.19).

Ao lermos na legislação palavras como "escola emancipadora e libertadora", entre outras, verificamos que, apesar do que o próprio sistema legislativo estabelece, a possibilidade, a título de exemplo, de discussões políticas (com viés não partidário) saudáveis, debates acerca da situação social do país e diversas outras atividades oportunas ao desenvolvimento intelectual atrelado aos desenvolvimentos humano e crítico-reflexivo, perdem, por vezes, espaço para o conteudismo e a neutralidade de práticas mecanicistas que precisam dar conta das cobranças por resultados, que visam aos bons resultados nas avaliações de larga escala. Vemos, portanto, uma grande contradição, de impactos claramente negativos, na consecução da formação pretendida.

Ainda assim, afora as variações político-econômicas, que parecem ditar o tipo de educação a ser ofertado, a escola é convidada a ser ainda mais participativa na busca por respostas às demandas de toda ordem. Vejamos as palavras de Libâneo, em resposta a uma entrevista concedida à revista Pensar a Prática, publicada no ano de 1998²:

PP: Professor Libâneo, num momento em que se fala muito em crise de paradigmas científicos, morais, éticos e na própria crise da educação, que papel a escola deve desempenhar no mundo contemporâneo?

Libâneo: Meu ponto de vista é o de que o mundo contemporâneo pede uma participação ainda maior da escola. Se valorizávamos a escola num momento em que tínhamos mais certezas em relação aos seus objetivos pedagógicos e políticos, especialmente na luta contra as desigualdades e a marginalização social, hoje ela aumenta de importância. O

\footnotetext{
${ }^{2}$ Entrevista concedida em 1997, publicada em 1998. Ver referências.
} 
mundo de hoje passa por transformações profundas nas esferas da economia, da política, da cultura, da ciência [...] (p.1, 1:1 21 jan./jun.1998).

Verifiquemos que, o que nas DNCEBs foi registrado, em 2013, acerca da ampliação das funções da escola, Libâneo já ressaltava anos antes. Destacamos a data da entrevista para fomentar no leitor a reflexão de que, se há 20 anos o mundo contemporâneo passava por mudanças, como diz o autor, após o avanço tecnológico e a praticidade e inovação dele decorrentes, modificando até mesmo as relações pessoais, a necessidade e importância da escola atualmente é ainda mais evidente.

À vista disso, a escola básica atual, pública, ainda que traga consigo tantos desafios e uma indesejada morosidade, continua sendo a esperança de uma vida mais digna, de uma sociedade mais igualitária aos que a ela recorrem. E, afora tantas dificuldades, deve honrar seu compromisso democrático, definido pelas palavras de Charlot (2013a, p.70) como: "evolução do indivíduo e modificação de suas relações com o ambiente social, ou ainda cultura e integração social; tal é o conteúdo mínimo da ideia de educação, tais são os dois aspectos [político e cultural] de toda educação, quaisquer que sejam as teorias pedagógicas nas quais se inspira". É nessa perspectiva que o professor passa a ser alvo de maiores cobranças, críticas, expectativas, tendo em vista ser o profissional que lida diária e diretamente com os sujeitos que chegam à escola ou, em outras palavras, “[...] os professores sofrem novas pressões sociais. Já que os resultados escolares dos alunos são importantes para as famílias e para o ‘futuro do país', os professores são vigiados, criticados” (Charlot, 2013b, p.97).

\section{Os Sujeitos da Nova Escola Básica}

No novo contexto acima apresentado, novos hábitos são exigidos pelos sujeitos, a despeito da classe social a qual fazem parte, tendo em vista todos serem, sob a nova lógica, consumidores e trabalhadores em potencial. Charlot (2013b) exemplifica tal realidade afirmando que "o autoatendimento nos bancos e nas estações de metrô, o uso da Internet, a compra de brinquedos eletrônicos para os seus filhos, até a escolha do seu hambúrguer por combinação de várias opções ou a faxina de escritórios cheios de conexões elétricas exigem modos de raciocínio outros que não os antigos" (Charlot, 2013b, p. 45).

Nessa direção, o autor esclarece que a escola recebe novos desafios, além de alunos com novos interesses, na medida em que são partes de uma sociedade com, também, novas perspectivas. O professor, portanto, acaba por ser o profissional incumbido de lograr os resultados esperados pelo Sistema e pela sociedade, tendo que assumir, para isso, o novo perfil que estes passaram a exigir dele. O que importa, na concepção de sucesso dessa sociedade, é que o professor encontre formas de "resolver os problemas na sua sala de aula e entregue alunos bem-sucedidos" (Charlot, 2013b, p. 46).

Libâneo (1998) propõe, na entrevista anteriormente mencionada, quatro sugestões para a escola atual, com vistas a atender às propostas de uma educação emancipadora, como a que propala, assegurando-nos de que as quatro formam uma unidade, dependendo, portanto, uma da outra. São elas: preparar o aluno para "o processo produtivo e a vida numa sociedade tecno-científica-informacional"; propiciar "meios de desenvolvimento de capacidades cognitivas e operativas, ou seja, ajudar os alunos nas competências do pensar autônomo, crítico e criativo"; formar os alunos para "a cidadania crítica e participativa"; educar os alunos, envolvendo toda a comunidade acadêmica numa "formação ética". Após o detalhamento de como poderia se dar, na prática, cada uma dessas propostas, o autor finaliza sua fala, afirmando a importância de "investir na capacitação efetiva para empregos reais e na formação do sujeito político socialmente responsável" (1998, p. 2). As referidas sugestões, muito embora sejam direcionadas à escola, atravessam a prática docente na medida em que aventam um novo modelo de formação dos sujeitos.

Tal modelo, apesar de compreensível, frente ao contexto já exposto, continua sendo laborioso, tendo em vista tantas questões que atravessam a escola, da ordem cultural, política, econômica que, nem sempre, ou quase nunca, dialogam entre si. 
Lembramos que, além disso, temos um sistema governamental que, por vezes, prioriza dados quantitativos em detrimento da qualidade, visando o bom posicionamento nos rankings educacionais. É nesse sentido que Charlot (2013b) afirma que o professor na sociedade atual é um "trabalhador da contradição" pois, entre outros fatores, "trabalha emaranhado em tensões e contradições arraigadas nas contradições econômicas, sociais e culturais da sociedade contemporânea" (Charlot, 2013b, p.102).

Lembremos ainda que, além das questões que se colocam dentro da própria escola e na interface da escola e da gestão mais ampla do sistema educacional, há também outros fatores agravantes que, apesar de não serem regra, são comuns na realidade escolar pública, tais como condições típicas da desestruturação familiar, falta de estrutura física e social, vulnerabilidade social, pouca ou nenhuma escolaridade dos familiares do aluno, contato com a violência doméstica, entre outras questões.

Não obstante, mantemo-nos firmes na busca por uma educação escolar que não se desligue dos valores sociais, entendidos não como valores a serem seguidos como forma de manutenção da ordem vigente, glorificando e enaltecendo classes sociais mais abastadas, em detrimento de minorias representativas, mas valores que tornam possíveis relações sociais saudáveis, atitudes éticas, consolidação da cidadania, desenvolvimento pessoal e, atrelado a este, desenvolvimento coletivo. Nessa perspectiva, concordamos com Rubem Alves ${ }^{3}$ quando diz que "a gente precisa mesmo é ter uma educação ligada com a vida”, e é com base nessa ligação, mais do que nunca, nos tempos líquidos (Bauman, 2009) de uma sociedade cada vez mais indiferente e carente de humanidade que "a escola tem a função de preparar cidadãos, mas não pode ser pensada apenas como tempo de preparação para a vida. Ela é a própria vida, um local de vivência da cidadania” (Alarcão, 2001, p. 18).

Sob essa mesma ótica, corroboramos as palavras de Gadotti (1992), ao afirmar que a escola é:

Um local de um sadio pluralismo de ideias, uma escola moderna; uma escola alegre, competente, científica, séria, democrática, crítica e comprometida com a mudança; uma escola mobilizadora, centro irradiador da cultura popular, à disposição da comunidade, não para consumi-la, mas para recriá-la. O saber adquirido na escola não é um fim em si mesmo, é um instrumento de luta pela transformação social (Gadotti, 1992, p. 75).

É nessa mesma expectação de transformação que Franco ${ }^{4}$ (2013, p.31) diz que "a escola precisa mais do que nunca de pensamentos críticos e revolucionários" e é por esse ângulo, por reconhecermos a escola como lugar do máximo de aprendizagens e compreendermos que a forma como se dão essas aprendizagens pode e deve ter impacto tanto na mudança da realidade do aluno de classe popular, como na mudança da sociedade de uma forma geral, contribuindo para que se torne mais justa, aberta ao respeito, adepta da empatia; por admitirmos a escola como lugar do máximo possível e não do mínimo, da criticidade, da mudança, é preciso mais do que o foco nos resultados e o cumprimento da legislação sob a camuflagem de uma falsa sensação de dever cumprido. Remetemo-nos, assim, à concepção de Paulo Freire, em sua obra Pedagogia da Autonomia, de que "educar é substantivamente formar" (2011, p.35).

Outrossim, é nesse sentido do educar, do formar, que concebemos a escola básica atual e os profissionais que nela atuam, em especial, os professores (e obviamente suas práticas) como uma ponte firme para o tipo de sociedade a que nos referimos, tendo em vista que, apesar de conscientes do vasto conjunto de mudanças e desafios que essa escola engloba, ainda acreditamos ser esse o melhor lugar de aprendizagens e oportunidades a todo e qualquer sujeito, sobretudo, aos desfavorecidos socialmente. Não na crença ingênua da resolução de todos os problemas, uma vez que, como afirma Libâneo (2006), a escola não tem a força para tornar iguais os que a realidade social e econômica tornou distintos, mas, quando numa perspectiva crítica, a escola "assume um papel de 'abrir os olhos' da classe dominada para que esta tome consciência de sua dominação e lute para a transformação social” (Libâneo, 2006, como citado em Franco, 2012, p. 92).

\footnotetext{
${ }^{3}$ Em entrevista concedida ao Programa Revista Digital, sem ano de referência. Ver referências.

${ }^{4}$ Em prefácio escrito na obra de Bernard Charlot (A mistificação pedagógica: Realidades sociais e processos ideológicos na teoria da educação - 2013). Ver referências.
} 


\section{Considerações Finais}

As reflexões acerca do panorama histórico da educação relacionada ao da política no Brasil, nos clareiam a percepção da escola que se faz presente nos dias atuais. A relevância de conhecermos as transformações nesses cenários, para além de compreendermos, enquanto nação, nosso próprio desenvolvimento histórico e social, é atentarmos para a estreita relação entre as concepções e decisões na esfera político-econômica e seus impactos diretos ou indiretos na esfera educacional.

As discussões aqui traçadas nos remetem à afirmação de Barguil (2007, p. 72), de que "a velocidade da Educação costuma ser muito menor do que as transformações na sociedade". Endossamos esse ponto de vista na medida em que, apesar do plexo entre as mudanças políticas, econômicas, sociais e educacionais, a escola atual ainda não conseguiu desprender-se inteiramente dos resquícios tradicionais que ainda norteiam sua estrutura, seu funcionamento e a prática de muitos que nela atuam. Falta-lhe, superando esses resquícios, abarcar uma educação que contemple os preceitos de um significativo desenvolvimento do aluno, na perspectiva humana tão requerida pelos documentos oficiais, mas, ao que nos parece, ao mesmo tempo tão minada pelo próprio sistema que elabora esses documentos. Falta uma efetiva formação que desenvolva competências e habilidades, obviamente - atendendo as demandas dos novos tipos de empregos, dessa nova sociedade, pautada na tecnologia - mas que esteja, simultaneamente, atenta a questões sociais, humanas, com encorajamento da autonomia, do senso crítico e, desta maneira, a possibilidade de uma efetiva sociedade plural, democrática.

É sabido que o compromisso e as reflexões do professor com e sobre sua prática diária e, junto a esta, com a educação de seus alunos, no que tange à dimensão formativa que aqui nos referimos, precisa ser permanente, quiçá inesgotável, o que não é fácil. Atentar para suas ações, para as individualidades discentes, para a riqueza de detalhes a serem pensados no planejamento, assim como ter a reflexão que possibilite a renovação constante de seu trabalho, bem como múltiplos olhares em sua própria prática, num espaço tão pouco valorizado pelo sistema e, lamentavelmente, pela sociedade, configura-se como um verdadeiro desafio, em meio a muitas contradições.

Por fim, sugerimos que, com vistas à continuidade e à ampliação de estudos sobre a temática aqui abordada, outras pesquisas sejam desenvolvidas. Investigações não só de cunho teórico, mas empírico, que busquem, por exemplo, conhecer e compreender a percepção de alunos e professores, em efetivo exercício nessa nova escola básica, sobre as mudanças e demandas a eles impostos, bem como as repercussões destas, a partir de suas narrativas.

\section{Referências}

Alarcão, I. (2001). A escola reflexiva. In A, Isabel. (Org.), Escola Reflexiva e Nova Racionalidade. Artmed Editora.

Alves, R. (s/a). Youtube. Entrevista concedida ao programa Revista Digital. https://www.youtube.com/watch?v=SkYE1JPwV Es\&list=PLMu1Bq4Kih4 OfOcKiyUnc2wnqXYdZkGOq\&index=3

Bauman, Z. (2009). Vida líquida. (2a ed.). Zahar.

Barguil, P. M. (2007). A didática nos cursos de licenciatura: O futuro educador e a avaliação contínua. In M. B. O. Ercília, G. F. Dorgival. (orgs.). Práticas e Aprendizagens Docentes. Cap. 3, pp. 57-78Edições UFC.

Brasil, Ministério da Educação. MEC. Novo ensino médio: perguntas e respostas. http://portal.mec.gov.br/component/content/article?id=40361

Charlot, B. A mistificação pedagógica: Realidades e processos ideológicos na teoria da educação. (Rev. ed. Coleção docência em formação: saberes pedagógicos). Cortez, 2013a.

Charlot, B. Da relação com o saber às práticas educativas. (1 ed. Coleção docência em formação: saberes pedagógicos). Cortez, 2013 b.

Constituição República Federativa do Brasil de 5 de outubro de 1988. (1988). Diário oficial da União. https://www.senado.leg.br/atividade/const/con1988/con1988_15.12.2016/CON1988.asp

Diretrizes Curriculares Nacionais para a Educação Básica. (2013). Ministério da Educação. Secretária de Educação Básica. MEC/SEB. Brasília, DF. http://portal.mec.gov.br/docman/julho-2013-pdf/13677-diretrizes-educacao-basica-2013-pdf/file

Franco, M. A. R. S. (2012). Pedagogia e prática docente. Coleção docência em formação: saberes pedagógicos. Cortez. 
Research, Society and Development, v. 10, n. 4, e29210414036, 2021

(CC BY 4.0) | ISSN 2525-3409 | DOI: http://dx.doi.org/10.33448/rsd-v10i4.14036

Franco, M. A. R. S. (2013). Por que republicar a mistificação pedagógica hoje? (prefácio). In C. Bernard. A mistificação pedagógica: Realidades e processos ideológicos na teoria da educação. (Cortez.

Freire, P. (2011). Pedagogia da autonomia: Saberes necessários à prática educativa.Paz e Terra.

Gadotti, M.(1992). Escola cidadã. Cortez.

González, F. E. (2020). Reflexões sobre alguns conceitos da pesquisa qualitativa. Revista Pesquisa Qualitativa. 8(17), 155-183. https://editora.sepq.org.br/rpq/article/view/322/200

Lei 9.394 de 20 de dezembro de 1996 (original). (1996a). Estabelece as diretrizes e bases da educação nacional. Brasília, DF. https://www2.camara.leg.br/legin/fed/lei/1996/lei-9394-20-dezembro-1996-362578-publicacaooriginal-1-pl.html

Lei 9.394 de 20 de dezembro de 1996 (modificada). (1996b). Estabelece as diretrizes e bases da educação nacional. Brasília, DF. http://www.planalto.gov.br/ccivil_03/leis/L9394compilado.htm

Lei 5.692 de 11 de agosto de 1971. (1971). Estabelece as diretrizes e bases da educação nacional. Brasília, DF. https://www2.camara.leg.br/legin/fed/lei/19701979/lei-5692-11-agosto-1971-357752-publicacaooriginal-1-pl.html

Lei 13.415 de 16 de fevereiro de 2017. (217). Altera as Leis $\mathrm{n}{ }^{\circ}$ 9.394, de 20 de dezembro de 1996, que estabelece as diretrizes e bases da educação nacional, e 11.494, de 20 de junho 2007, que regulamenta o Fundo de Manutenção e Desenvolvimento da Educação Básica e de Valorização dos Profissionais da Educação, a Consolidação das Leis do Trabalho - CLT, aprovada pelo Decreto-Lei ${ }^{\circ} 5.452$, de $1^{\circ}$ de maio de 1943, e o Decreto-Lei $\mathrm{n}^{\circ} 236$, de 28 de fevereiro de 1967; revoga a Lei no 11.161 , de 5 de agosto de 2005; e institui a Política de Fomento à Implementação de Escolas de Ensino Médio em Tempo Integral. Brasília, DF. http://www.planalto.gov.br/ccivil_03/_Ato2015-2018/2017/Lei/L13415.htm

Libâneo, J. C. (1998). Perspectivas de uma Pedagogia emancipadora face às transformações do mundo contemporâneo. Revista Pensar a Prática, 1(1), 1-22. https://www.revistas.ufg.br/fef/article/view/8/7

Minayo, M. C. S. (2016). O desafio da pesquisa social. In S. M. Maria Cecília (org.), F. D. Suely, G. Romeu. Pesquisa social: teoria, método e criatividade. Série Manuais Acadêmicos. pp. 9-28. Vozes.

Nóvoa, A. (2007). Desafios do trabalho do professor no mundo contemporâneo. Sindicato dos Professores de São Paulo - SINPRO. SP, 2007. http://www.sinprosp.org.br/arquivos/novoa//ivreto_novoa.pdf

Pereira, A. S., Shitsuka, D. M., Parreira, F. J. \& Shitsuka, R. (2018). Metodologia da pesquisa científica (recurso eletrônico, 1a. ed., pp.119), Santa Maria, RS: UFSM, NTE. https://repositorio.ufsm.br/bitstream/handle/1/15824/Lic_Computacao_Metodologia-Pesquisa-Cientifica.pdf?sequence=1\&isAllowed=y

Resolução CNE/CP $n^{o}$ 2, de 22 de dezembro de 2017. (2017). Institui e orienta a implantação da Base Nacional Comum Curricular, a ser respeitada obrigatoriamente ao longo das etapas e respectivas modalidades no âmbito da Educação Básica. Brasília, DF. http://portal.mec.gov.br/index.php?option=com_docman\&view=download\&alias=79631-rcp002-17-pdf\&category_slug=dezembro-2017-pdf\&Itemid=30192

Resolução CNE/CP $n^{o}$ 3, de 21 de novembro de 2018. (2018). Atualiza as Diretrizes Curriculares Nacionais para o Ensino Médio. Brasília, DF. http://novoensinomedio.mec.gov.br/resources/downloads/pdf/dcnem.pdf 